\title{
Isolation and Identification of Indigenous Wine Yeasts and Their Use in Alcoholic Fermentation
}

\section{Polona Zabukovec ${ }^{\top} \odot$, Neža

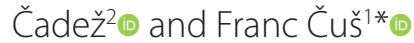

'Agricultural Institute of Slovenia, Department of Fruit Growing, Viticulture and Oenology, Hacquetova ulica 17, 1000 Ljubljana, Slovenia

2Department of Food Science and Technology, Chair of Biotechnology, Microbiology and Food Safety, Biotechnical Faculty, Jamnikarjeva ulica 101, 1000 Ljubljana, Slovenia

Received: 24 February 2020 Accepted: 7 August 2020

\section{SUMMARY}

Research background. In our study, spontaneous alcoholic fermentations were carried out to isolate non-Saccharomyces and Saccharomyces yeasts from grape must from different vine-growing regions in Slovenia. Additionally, the diversity of native Saccharomyces cerevisiae strains was evaluated during the process.

Experimental approach. During spontaneous alcoholic fermentations the yeast population of non-Saccharomyces and Saccharomyces yeasts was sampled. We used eleven microsatellite markers to determine the genetic diversity of $S$. cerevisiae strains. In addition, different ratios of the indigenous strains of $S$. cerevisiae, Hanseniaspora uvarum and Starmerella bacillaris were tested for their possible use in alcoholic fermentation with inoculated yeasts by monitoring its course and measuring the concentration of aroma compounds in wine.

Results and conclusions. Sequencing of the internal transcribed spacer (ITS) regions of ribosomal DNA showed that of 64 isolates, 46 strains represent $S$. cerevisiae and 18 strains belong to non-Saccharomyces yeasts. The identified non-Saccharomyces yeast species were H. uvarum, Pichia kudriavzevii, Saturnispora diversa and S. bacillaris. The dendrogram grouped $S$. cerevisiae strains into 14 groups. The number of $S$. cerevisiae strains isolated from the musts was 10 (Posavje), 11 (Podravje) and 25 (Primorska vine-growing region). On the other hand, the alcoholic fermentation with inoculated yeasts, in which the native S. cerevisiae strain predominated over H. uvarum and S. bacillaris, gave the most promising result due to the highest alcohol volume fraction, the lowest acetic acid concentration and significantly higher concentrations of volatile thiols 3-mercaptohexyl acetate (3MHA) and 3-mercaptohexan-1-ol (3MH), 2-methylpropanol, 2-methylbutanol, 3-methylbutanol and 2-phenylethanol) in the produced wine.

Novelty and scientific contribution. We confirmed the potential use of indigenous S. cerevisiae and non-Saccharomyces yeasts in alcoholic fermentation with inoculated yeasts, which allows the positive properties of the yeast strains to be expressed and good quality wines to be produced. Thus, the results are encouraging for winemakers to create different wine styles associated with a particular terroir using indigenous yeasts.

Key words: spontaneous alcoholic fermentation, non-Saccharomyces yeasts, Saccharomyces yeasts, starter cultures, wine aroma compounds

\section{INTRODUCTION}

Spontaneous alcoholic fermentation is a process of many biochemical changes, due to external physical factors and the biological activities of fermenting microorganisms that include various species/strains of non-Saccharomyces and Saccharomyces yeasts $(1,2)$. It usually begins with non-Saccharomyces yeasts, and the mainly present genera are Hanseniaspora, Starmerella, Pichia, Debaryomyces and Metschnikowia. They prevail on the surface of grape berries, and have a weak ability to ferment sugars in the must $(3,4)$. When the fermentation begins, the exponential growth phase of the genera Hanseniaspora, Candida and Pichia yeasts is limited from two to three days, and after that, they reach a stationary phase. At later stages of the alcoholic fermentation, S. cerevisiae dominates the non-Saccharomyces strains, and completes the fermentation. 
In spontaneous alcoholic fermentation, indigenous yeasts add the desired specific regional characteristics, but on the other hand, they might increase the risk of a stuck fermentation $(5,6)$. The microorganisms present in the wine influence its chemical composition, and among them yeasts, especially S. cerevisiae, play the key role, leading the alcoholic fermentation. In stressful conditions of winemaking, S. cerevisiae shows better adaptation to the winemaking conditions by growing faster and with high biomass productivity, which is correlated to higher viability in the late fermentation phases than with strains isolated from other environments (1). The main reasons for the dominance of $S$. cerevisiae yeast during alcoholic fermentation are the resistance to higher volume fractions of ethanol, and the ability to grow under anaerobic conditions $(7,8)$. The $S$. cerevisiae strains from different genetical backgrounds differ in these characteristics and play an important role in determining the sensory quality of wine $(6,9)$.

Indigenous Saccharomyces yeasts isolated from grapes can emphasise the specificity of the terroir, and can contribute to an increased market visibility of wine, due to their production of aromatic compounds which are formed during the fermentation, including higher alcohols, esters, terpenes and volatile thiols $(8,9)$. With spontaneous alcoholic fermentation, we can obtain a greater quantity of compounds that significantly affect the sensory properties of the wine, which in general, have lower alcohol and/or residual sugar concentrations (10).

The quality of the wine produced by spontaneous alcoholic fermentation depends on the microbial population ecology of the grapes (6). Its characteristic is that indigenous yeast strains are better adapted to the chemical and microbiological properties of must in a given ecological environment $(11,12)$. The grapevine cultivar, viticultural and oenological practices, macro- and microclimatic conditions and the geographic location of the vineyards mainly affect yeast biodiversity (13-15). In Slovenia, there are three vine-growing regions, Primorska, Podravje and Posavje with different pedoclimatic conditions influencing grapevine. Different vine-growing regions and grapevine cultivars may also delimit yeast populations and affect the genetic and phenotypic diversity of the yeasts $(14,16,17)$.
Various studies have shown significant molecular polymorphisms of the indigenous $S$. cerevisiae strains from different vine-growing regions, and a strong correlation between their genomic and phenotypic properties (13,18-20). These yeasts might be better adapted to the fermentation of a particular grape and contribute to the typical oenological characteristics of a particular region (2). By using new tools for determining the wine yeast biodiversity, we can today better predict the characteristics of the wines with regard to terroir $(21,22)$. Therefore, research on wine yeast biodiversity should be further implemented with new molecular and oenological approaches to enable winemakers to mimic spontaneous alcoholic fermentation, which would preserve the distinctive characteristics of their wines in correlation with the terroir properties.

Therefore, the objective of the study is to isolate indigenous non-Saccharomyces and Saccharomyces wine yeast strains from the must derived from three Slovenian vine-growing regions for their potential use as regional starter cultures and consequently to obtain wines with certain sensory characteristics that can be linked to the terroir.

\section{MATERIALS AND METHODS}

\section{Grape sampling and spontaneous alcoholic fermentation}

Undamaged and healthy grapes of different varieties, Malvazija (syn. Malvasia), Merlot, Refošk (syn. Refosco), Chardonnay, Šipon (syn. Furmint), Zweigelt, Modra frankinja (syn. Blaufränkisch) and Kerner were aseptically collected on different sampling dates in September 2016 (Table 1) in sterile plastic bags in three replicates (approx. $2 \mathrm{~kg}$ per replicate) from the vine-growing regions of Primorska ( 3 varieties $\times 3=9$ samples), Posavje ( 2 varieties $\times 3=6$ samples) and Podravje ( 4 varieties $\times 3=12$ samples), and processed separately in the laboratory.

The must was treated with Redox Arom, a mixture of antioxidants: L-ascorbic acid $35 \%$, K-metabisulphite $55 \%$ and purified gallotannins $10 \%$ (DAL CIN GILDO S.p.A., Concorezzo, Italy) to protect it from the action of oxygen in the must. The mixture was added into the bags in the amount of 0.2

Table 1. List of grape varieties by vine-growing region, location, sampling date and chemical parameters in must

\begin{tabular}{|c|c|c|c|c|c|c|}
\hline Vine-growing region & $\begin{array}{l}\text { Sampling } \\
\text { location }\end{array}$ & $\begin{array}{l}\text { Sampling } \\
\text { date }\end{array}$ & Variety & $\gamma($ sugar $) /(g / L)$ & $\begin{array}{c}\gamma \text { (total acidity)/ } \\
(\mathrm{g} / \mathrm{L})\end{array}$ & $\mathrm{pH}$ \\
\hline \multirow{3}{*}{ Primorska } & \multirow{2}{*}{ a } & 8.9.2016 & MAL & $252.5 \pm 9.4$ & $4.4 \pm 0.2$ & $3.61 \pm 0.08$ \\
\hline & & 8.9.2016 & MER & $237.0 \pm 8.8$ & $4.2 \pm 0.3$ & $3.48 \pm 0.09$ \\
\hline & $b$ & 14.9.2016 & $\mathrm{R}$ & $272.2 \pm 31.6$ & $7.6 \pm 0.6$ & $3.18 \pm 0.07$ \\
\hline \multirow{2}{*}{ Posavje } & \multirow{2}{*}{ c } & 15.9.2016 & K & $240.7 \pm 32.3$ & $5.6 \pm 0.3$ & $3.21 \pm 0.04$ \\
\hline & & 15.9.2016 & MF & $208.2 \pm 5.2$ & $6.5 \pm 0.3$ & $3.26 \pm 0.04$ \\
\hline \multirow{4}{*}{ Podravje } & $d$ & 20.9.2016 & $\mathrm{CH}$ & $214.5 \pm 1.3$ & $5.6 \pm 0.6$ & $3.33 \pm 0.04$ \\
\hline & e & 26.9.2016 & $\check{S}$ & $160.0 \pm 3.9$ & $8.9 \pm 0.9$ & $3.13 \pm 0.02$ \\
\hline & \multirow{2}{*}{$f$} & 26.9.2016 & ZW & $202.0 \pm 2.5$ & $5.6 \pm 0.1$ & $3.40 \pm 0.01$ \\
\hline & & 26.9.2016 & MF & $191.1 \pm 12.9$ & $8.2 \pm 0.7$ & $3.13 \pm 0.09$ \\
\hline
\end{tabular}

Sampling locations: $a=$ Debeli Rtič, $b=S ̌ k o f i j e, ~ c=$ Pleterski hrib, $d=$ Svetinje, $e=$ Ivanjkovci, $f=$ Mačkovci; varieties: $M A L=$ Malvasia, MER=Merlot, $\mathrm{R}=$ Refosco, $\mathrm{K}=$ Kerner, $\mathrm{MF}=$ Blaufränkisch, $\mathrm{CH}=$ Chardonnay, $\breve{S}=$ Furmint, $\mathrm{ZW}=\mathrm{Z}$ weigelt, $M F=$ Blaufränkisch 
$\mathrm{g} / \mathrm{kg}$ of grapes. The grape juice was obtained after destemming, crushing and squeezing the grapes in a sterile inox container.

The must was poured into 1-litre sterile fermentors. Spontaneous alcoholic fermentations were performed at room temperature $\left(21-23^{\circ} \mathrm{C}\right)$, monitored by weighing the fermentors and calculating the amount of released $\mathrm{CO}_{2}$.

\section{Measurement of must parameters}

Sugar concentration, total acidity and $\mathrm{pH}$ value were determined in the musts. The sugar concentration was measured by WineLab touch (CDR s.r.l., Ginestra Fiorentina, Florence, Italy). The total acidity and $\mathrm{pH}$ values were determined by the methods accredited in the laboratory (OIV-MA-AS31301:R2015 (23) and OIV-MA-AS313-15:R2011 (24)).

\section{Yeast sampling, isolation and identification}

During the spontaneous alcoholic fermentation, must aliquots were aseptically sampled and expected countable dilutions were plated on Wallerstein Laboratory (WL) nutrient agar (Merck, Darmstadt, Germany) in two replicates, in order to determine colony counts and to morphologically distinguish between non-Saccharomyces and Saccharomyces yeasts. The first sampling was carried out on the fifth day of spontaneous alcoholic fermentation, in order to obtain a first count of the non-Saccharomyces yeast population. Further samplings followed the dynamics of fermentations, and were taken in the middle and at the end of the fermentations.

After incubation at $26{ }^{\circ} \mathrm{C}$ for $2-3$ days, the colonies were counted, and grouped depending on their morphology (OIV-MA-AS4-01:R2010) (25). Selected representatives of different morphological groups of yeasts were purified on yeast-malt (YM) agar plates (yeast extract $3.0 \mathrm{~g} / \mathrm{L}$ (Biolife, Milano, Italy), malt extract $3.0 \mathrm{~g} / \mathrm{L}$ (Biolife), peptone $5.0 \mathrm{~g} / \mathrm{L}$ (Biolife), glucose $30.0 \mathrm{~g} / \mathrm{L}$ (Merck), agar $20.0 \mathrm{~g} / \mathrm{L}$ (Biolife)), with $0.01 \%$ chloramfenicol (Merck) added. The strains were cryopreserved in $10 \%$ glycerol (Merck) at $-80^{\circ} \mathrm{C}$.

\section{Molecular identification of yeast species}

The total DNA was isolated using the MasterPure ${ }^{\mathrm{TM}}$ Yeast DNA Purification Kit (Illumina, San Diego, CA, USA). The primers used for amplification of internal transcribed spacer (ITS) regions and D1/D2 region of large subunit (LSU) rDNA were ITS1 (5` TCCGTAGGTGAACCTGCGG) and NL4 (5` GGTCCGTGTTTCAAGACGG) as described, respectively, by White et al. (26) and Kurtzman and Robnett (27). The final volume of the polymerase chain reaction (PCR) on the mixture was $50 \mu \mathrm{L}$ containing 100 ng genomic DNA, 1×standard buffer $\mathrm{Mg}^{2+}$ free, $1.5 \mathrm{mM}$ $\mathrm{MgCl}_{2}, 2 \mathrm{mM}$ of each dNTP, $50 \mathrm{pM}$ of each of a pair of primers and $1 \mathrm{U}$ Taq DNA polymerase (Promega, Madison, WI, USA).

For amplification of ITS rDNA, the PCR conditions were as follows: an initial denaturing step of $5 \mathrm{~min}$ at $94{ }^{\circ} \mathrm{C}$ was followed by 35 cycles of $40 \mathrm{~s}$ at $94^{\circ} \mathrm{C}, 40 \mathrm{~s}$ at $56^{\circ} \mathrm{C}$ and $30 \mathrm{~s}$ at 72
${ }^{\circ} \mathrm{C}$ and terminated with a final extension step of $7 \mathrm{~min}$ at $72{ }^{\circ} \mathrm{C}$ and cooling down to $4^{\circ} \mathrm{C}$. The amplicon was sequenced by the commercial sequencing facilities (Macrogen Inc., Amsterdam, The Netherlands). The sequences were aligned and trimmed using BioNumerics v. 7.6 (28). For the molecular identification of yeast isolates, BLAST tools against GenBank recordings (29) of the rDNA sequences of the reference/type strains were used. All different sequences of the isolates were deposited in the GenBank and their accession numbers are listed in Table S1.

\section{Analysis of microsatellite repeats}

To evaluate the genetic diversity of $S$. cerevisiae strains, their microsatellite regions were analysed according to Legras et al. (30). Two multiplex PCR reactions for amplification of loci C5, C3, C8, C11, SCYOR267c and YKL172w, ScAAT1, C4, SCAAT5, C6, YPL009c by using Qiagen Multiplex Master Mix (Qiagen, Hilden, Germany) were performed. The size of the fluorescently labelled PCR products was determined by capillary gel electrophoresis in a commercial laboratory (Macrogen, Seoul, South Korea). The number of repeats in the microsatellite loci was automatically determined by a multiple-locus variable-number tandem repeat analysis (MLVA) module of the BioNumerics v. 7.6 software (28). The results were then manually curated. A dendrogram of similarity was created using the Bay-Curtis algorithm and clustering unweighted pair group method with arithmetic mean analysis (UPGMA). All isolates were genotyped using eleven microsatellite loci.

\section{Measurement of chemical parameters of wine}

After the completion of alcoholic fermentation, $2 \mathrm{~mL} / \mathrm{L}$ of 5-6\% sulphuric acid (Agrolit, Litija, Slovenia) were added to each fermentor, and later, the wine was transferred into bottles and placed in cold storage for clarification. The principle chemical parameters of wine (alcohol, glycerol, acetic acid, total and free $\mathrm{SO}_{2}$ ) were measured after one month of storage by WineLab Touch (CDR s.r.I.), where the measurements are based on enzymatic reactions for a single parameter according to the manufacturer's instructions.

\section{Mixed alcoholic fermentation using indigenous strains}

In the following experiment, we tested the fermentation capacity and efficiency of three previously isolated indigenous strains of Saccharomyces cerevisiae (RM1), Hanseniaspora uvarum (RM2) and Starmerella bacillaris (RM3). They showed a good potential to form volatile compounds (thiols, ethyl acetate, acetaldehyde and higher alcohols) during spontaneous alcoholic fermentation of Moscato bianco must, from which they were isolated and identified (9). The fermentation performance of these three indigenous strains was tested in Sauvignon must, in the following experiments: experiment A (33\% S. cerevisiae, $33 \%$ H. uvarum, $33 \%$ S. bacillaris), experiment B (20\% S. cerevisiae, $40 \%$ H. uvarum, $40 \%$ S. bacillaris) and experiment C ( $80 \%$ S. cerevisiae, $10 \%$ H. uvarum, $10 \%$ S. bacillaris). The fermentations 
were performed in 1000-mL glass fermentors in two replicates at $(17.5 \pm 0.5)^{\circ} \mathrm{C}$. The must had the following parameters: sugar concentration $207 \mathrm{~g} / \mathrm{L}$, total acidity $6.2 \mathrm{~g} / \mathrm{L}$, yeast assimilable nitrogen concentration $208 \mathrm{mg} / \mathrm{L}$, and $\mathrm{pH}=3.21$. The alcoholic fermentations were monitored by measuring mass loss. Must aliquots for plating were aseptically taken at the beginning, in the middle, and at the end of fermentation, and then plated on WL nutrient agar (Merck KGaA), in order to morphologically distinguish between inoculated non-Saccharomyces and Saccharomyces yeasts.

\section{Measurement of aromatic compounds in wine}

At the end of the alcoholic fermentation, the chemical parameters and the content of the aromatic compounds were measured in the wines. The basic chemical parameters of wine were measured by WineLab Touch (CDR s.r.I.), where measurement is based on enzymatic reactions. The concentrations of volatile thiols (4-mercapto-4-methyl-pentan-2-one (4MMP), 3-mercaptohexan-1-ol (3MH) and 3-mercaptohexyl acetate (3MHA)) were measured two weeks after the completion of the fermentation on the GC-MS system. Hydroxy mercury benzoate ( $5 \mathrm{~mL}$ of a 2-mM solution) and butylated hydroxylanisole $(0.5 \mathrm{~mL}$ of a $0.02-\mathrm{mM}$ solution) were added to $50 \mathrm{~mL}$ of the wine sample. After mixing for $1 \mathrm{~min}$, internal standards 4-methoxy-2-methyl-2-mercaptobutane (4M2M2MB), deuterated 3-mercaptohexan-1-ol (d3MH) and deuterated 3-mercaptohexyl acetate (d3MHA) were added, and the procedure continued according to the method described by Jenko et al. (31).

Ethyl acetate, acetaldehyde and higher alcohols were measured using the methods described by Bavčar et al. (32). The wine samples were diluted (1:4) with water (Milli-Q, Millipore, Billerica, MA, USA) to achieve a 1:3 ratio between the liquid and the headspace of a $20-\mathrm{mL}$ solid space microextraction (SPME) vial. The samples were incubated at $40^{\circ} \mathrm{C}$ for $1 \mathrm{~h}$, and adsorbed to a polydimethylsiloxane/divinylbenzene (PDMS/ DVB) fibre (Supelco, Bellefonte, PA, USA). The compounds were identified and quantified with a gas chromatograph (Agilent 7890A; Agilent Technologies, Palo Alto, CA, USA), equipped with an automatic multipurpose sampler MPS 2 (Gerstel, Mülheim and der Ruhr, Germany) and coupled with a mass spectrometer (Agilent 5975C; Agilent Technologies).

\section{Statistical analysis}

The results were tested for normality distribution by Shapiro-Wilk test and statistically analysed using ANOVA in Statgraphics ${ }^{\circledR}$ Centurion XVI software (33).

\section{RESULTS AND DISCUSSION}

\section{Chemical composition of the musts}

During the harvest, grape samples of the representative grape varieties for each vine-growing region in Slovenia were collected and processed. As detailed in Table 1, the chemical parameters of the musts differed depending on grape variety and vine-growing region. The lowest concentration of total acids in musts from white varieties and the highest concentrations of sugars were found in musts from the Primorska region, which has a Mediterranean climate. However, generally the highest total acid concentrations and the lowest densities were characteristic of the Podravje region musts, which have a cooler climate. If we take a closer look at the must parameters, they are mainly linked to the varietal characteristics, e.g. Refosco in Primorska, with a higher value for total acidity, and Kerner, Chardonnay and Zweigelt, with lower values in regions Posavje and Podravje.

\section{Fermentation kinetics of the musts}

Using the collected grape samples, 27 spontaneous alcoholic fermentations were conducted. The amount of exhausted $\mathrm{CO}_{2}$ was more intense in the fermentors with varieties from the Primorska vine-growing region, on average $12.49 \mathrm{~g}$ per $100 \mathrm{~mL}$ of must (Fig. 1a), which is also a consequence of higher initial sugar concentration in the must (Table 1). All spontaneously fermented wine samples from the Primorska vine-growing region had a content of reducing sugars below $42 \mathrm{~g} / \mathrm{L}$ when the fermentation stopped. In the fermentors with the must from the Posavje vine-growing region (Fig. 1b), the average final mass of exhausted $\mathrm{CO}_{2}$ was $9.6 \mathrm{~g}$ and in the fermentors from the Podravje vine-growing region $8.7 \mathrm{~g}$ per $100 \mathrm{~mL}$ of must (Fig. 1c). The eight samples (two fermentors containing Blaufränkisch (MF) variety from the Posavje vine-growing region, and three fermentors with Blaufränkisch (MF) variety, two fermentors with Furmint (Š) variety and one fermentor with Zweigelt $(Z W)$ variety from the Podravje vine-growing region) did not reach the stationary phase after 45 days of spontaneous alcoholic fermentation, because the fermentation got stuck.

The nutritional status of must is an important parameter that influences the alcoholic fermentation $(10,21)$. In our case, we noticed the poor kinetics of alcoholic fermentations and yeast efficiency, probably due to the poor nutritional status of the must together with a specific yeast population that developed in each fermentor and led to the stuck fermentation.

\section{Abundance of yeasts and their identification}

We isolated altogether 64 isolates for further identification: 46 Saccharomyces and 18 non-Saccharomyces yeast (Table S1) and determined their macro- and micromorphology. The count of yeasts was determined at different sampling points; however, none of the Saccharomyces and non-Saccharomyces yeasts were isolated from the third sampling (Table 2).

The percentage of similarity between the ITS and D1/D2 sequences of the species type strains and our isolates (representatives of each group) with the GenBank accession numbers is shown in Table S1. The identified non-Saccharomyces yeast species were Hanseniaspora uvarum (five strains), Pichia kudriavzevii (three strains), Saturnispora diversa (two strains), and Starmerella bacillaris (syn. Candida zemplinina) (eight strains). H. uvarum 

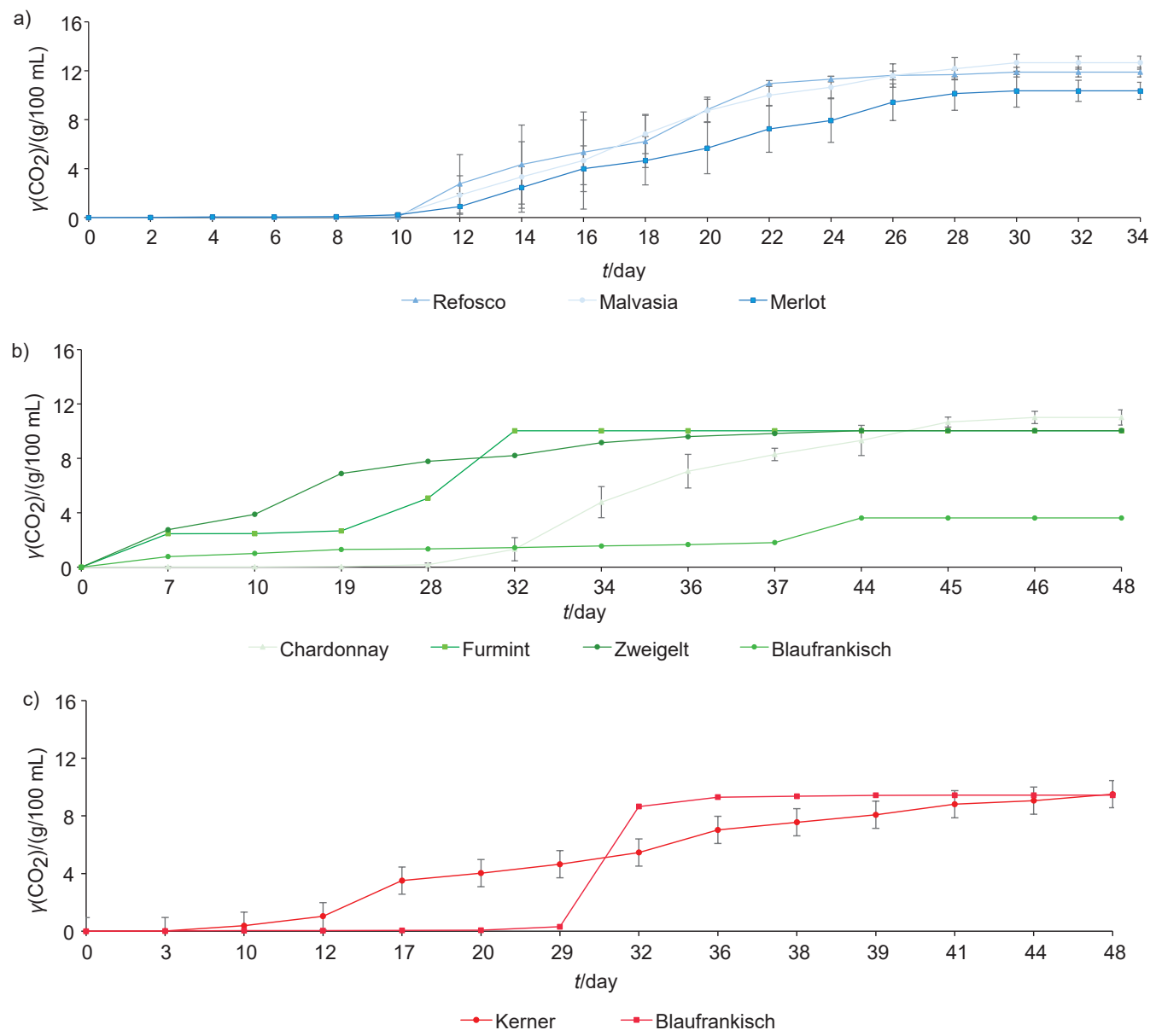

Fig. 1. Mass concentration of exhausted $\mathrm{CO}_{2}$ in spontaneous alcoholic fermentation of: a) Refosco, Malvasia and Merlot (Primorska vine-growing region) (average values \pm S.D. are shown), b) Kerner (average values \pm S.D. are shown) and Blaufränkisch (one fermentation completed) (Posavje vine-growing region), c) Chardonnay (three fermentations completed), Zweigelt (two fermentations completed), Furmint (one fermentation completed), and Blaufränkisch (none fermentation completed) (Podravje vine-growing region) (average values \pm S.D. are shown for Chardonnay and Zweigelt)

Table 2. Average yeast counts ( $N(\log \mathrm{CFU} / \mathrm{mL}$ ) in all spontaneous alcoholic fermentations from each region and the number of yeast isolates obtained at the beginning (I.), in the middle (II.) and at the end (III.) of all fermentations per region

\begin{tabular}{|c|c|c|c|c|c|c|}
\hline \multirow{2}{*}{$\begin{array}{l}\text { Region/ } \\
\text { Sampling }\end{array}$} & \multicolumn{2}{|r|}{ Primorska } & \multicolumn{2}{|r|}{ Posavje } & \multicolumn{2}{|r|}{ Podravje } \\
\hline & $N(\log C F U / m L)$ & $\begin{array}{c}N(\text { S. cerevisiae }) / \\
N(\text { non-Saccharomyces sp.) }\end{array}$ & $N(\log C F U / m L)$ & $\begin{array}{c}N(S . \text { cerevisiae)/ } \\
N(\text { non-Saccharomyces sp.) }\end{array}$ & $N(\log C F U / m L)$ & $\begin{array}{c}N(S . \text { cerevisiael } \\
N(\text { non-Saccharomyces sp.) }\end{array}$ \\
\hline I. & 3.6 & $0 / 2$ & 3.3 & $0 / 6$ & 3.8 & $0 / 10$ \\
\hline II. & 6.5 & $25 / 0$ & 5.7 & $10 / 0$ & 6.4 & $11 / 0$ \\
\hline III. & 6.1 & 0 & 0 & 0 & 5.9 & 0 \\
\hline
\end{tabular}

is one of the prevailing apiculate yeast species in wine grapes from warm vine-growing regions, and was isolated only from Merlot must at the beginning of alcoholic fermentation. Yanagida et al. (34) also found the species to be a typical constituent of the yeast microbiota under mild climatic conditions.

Non-Saccharomyces strains of oenological interest were isolated from the must of Furmint variety. Although the fermentation was stuck in two fermentors, we obtained three representatives of H. uvarum and three of P. kudriavzevii. Nemcová et al. (35) reported that in their research, $P$. kudriavzevii isolated from Blaufränkisch variety, was more associated with damaged than with intact grapes. The third most common
non-Saccharomyces yeast was S. bacillaris and was isolated as a representative from Kerner must, three from Blaufränkisch must from Posavje and two from Podravje. We should stress that our intention was to get a diverse population of S. cerevisiae strains, and not to get an excess population of non-Saccharomyces isolates.

\section{Chemical composition of wines}

When the concentration of reducing sugars dropped below $45 \mathrm{~g} / \mathrm{L}$, we stopped spontaneous alcoholic fermentation by adding sulphur to the wine (varieties from Primorska on 
the 34th day, varieties from Posavje on the 48th day and varieties from Podravje on the 46th day). Later on, some chemical components in the wines were measured. Table 3 shows the differences among the wines of different grape varieties, as a result of Saccharomyces and non-Saccharomyces yeasts present in the fermenting must. Interestingly, for all wine samples, the volatile acid concentration was below $1 \mathrm{~g} / \mathrm{L}$.

\section{Genetic diversity of S. cerevisiae populations}

In order to investigate the genetic diversity of S. cerevisiae, polymorphisms in eleven microsatellite regions of 46 strains were determined, and are shown in the dendrogram of similarity (Fig. 2). The dendrogram clustered S. cerevisiae strains into 14 groups at a similarity level of $99 \%$. As reported by Schuller et al. (12), many S. cerevisiae strains were homozygous, although in our case, many were heterozygous, indicating outcrossing between different populations.

The numbers of Saccharomyces cerevisiae strains isolated from the musts were 10 (Posavje), 11 (Podravje) and 25 (Primorska). We did not isolate $S$. cerevisiae strains from the spontaneous alcoholic fermentations of Furmint and Blaufränkisch must.

Genetically identical strains in all loci, S. cerevisiae R3164 and S. cerevisiae MAL383 (group 9), were isolated from two different vineyards in the Primorska vine-growing region, and were heterozygous in loci ScAAT1, C4, C6, YPL009c, C5 and C8. Interestingly, the strains S. cerevisiae Mer183 and S. cerevisiae K1162, belonging to group 9, were isolated from different vine-growing regions, and were identical in all loci. Group 9 comprised eight strains of $S$. cerevisiae, of which six strains were isolated from the Primorska vine-growing region. Genetically the most closely related strains from one variety in this group were isolated from the Refosco must. Otherwise, the genetically diverse group of strains (group 7), isolated from the varieties of the Primorska, Posavje and Podravje vine-growing regions, were identical in two motifs (37/37 and 21/22) of microsatellite loci ScAAT1 and C4.
Genetically similar strains of group 14, S. cerevisiae K3161, S. cerevisiae K2163 and S. cerevisiae K2162, were isolated from the Posavje vine-growing region, and coincided in all microsatellite loci (K3161 and K2163), except C3 (K2162). S. cerevisiae MAL384 and S. cerevisiae $\mathrm{CH} 1213$ (group 12) were isolated from different vine-growing regions, and differed in $\mathrm{C4}$ and C3 loci only.

Strains from the Primorska vine-growing region had characteristic microsatellite loci YKL172w and C4 with seven repeats of the motif ( 7 out of 13 strains). Strains from the Podravje vine-growing region also had the characteristic microsatellite loci YKL172w and ScAAT5, with eight repeats of the motif (8 out of 12 strains).

In Slovenian yeast populations, from two to 22 different alleles were detected in a single microsatellite locus. The largest number of alleles, and thus the highest diversity of S. cerevisiae, were shown by microsatellite loci C5, YPL009c, C3 and SCAAT1. As reported by other authors $(20,36)$, microsatellite loci C3, C5 and ScAAT1 are most commonly used to describe the genotype of $S$. cerevisiae present in complex samples such as must.

\section{Chemical composition of the wines produced by indigenous yeast strains}

To observe the ability and efficiency of isolated indigenous yeasts to conduct wine fermentations as starter cultures, we continued our study with three previously isolated yeasts of Saccharomyces and non-Saccharomyces yeasts. Fig. 3 shows the mass fraction of exhausted $\mathrm{CO}_{2}$ during alcoholic fermentation inoculated with different initial ratios of indigenous yeasts. As expected, the weakest fermentation kinetics in experiment $B$ was with the lowest ratio of S. cerevisiae and vice versa, the most intensive in experiment $C$ with the highest ratio of $S$. cerevisiae. Slightly less intensive was the fermentation kinetics in experiment $A$ with an equal ratio of all three yeast species.

Alcoholic fermentations with different combinations of indigenous yeast strains were stopped after 35 days, when

Table 3. Chemical composition of the wines obtained by spontaneous alcoholic fermentation

\begin{tabular}{|c|c|c|c|c|c|c|c|c|c|c|}
\hline \multirow[b]{2}{*}{$\begin{array}{l}\text { Vine } \\
\text { region }\end{array}$} & \multirow[b]{2}{*}{ Grape variety } & \multicolumn{2}{|c|}{$N$ (isolated yeasts) } & \multicolumn{7}{|c|}{ Chemical parameter } \\
\hline & & $\begin{array}{c}\text { S. } \\
\text { cerevisiae }\end{array}$ & $\begin{array}{c}\text { Non- } \\
\text { Saccharomyces } \\
\text { sp. }\end{array}$ & $\varphi($ alcohol $) / \%$ & $\begin{array}{c}\gamma(\text { glycerol }) / \\
(\mathrm{g} / \mathrm{L})\end{array}$ & $\begin{array}{c}\gamma(\text { acetic } \\
\text { acid)/(g/L) }\end{array}$ & $\begin{array}{c}\gamma(\text { malic } \\
\text { acid }) /(g / L)\end{array}$ & $\begin{array}{c}\gamma\left(\text { free } \mathrm{SO}_{2}\right) / \\
(\mathrm{mg} / \mathrm{L})\end{array}$ & $\begin{array}{c}\gamma\left(\text { total } \mathrm{SO}_{2}\right) / \\
(\mathrm{mg} / \mathrm{L})\end{array}$ & $\begin{array}{c}\gamma \text { (reducing } \\
\text { sugars)/ } \\
\text { (g/L) }\end{array}$ \\
\hline \multirow{3}{*}{ Primorska } & Malvasia* & 7 & 0 & $14.7 \pm 0.7$ & $8.8 \pm 0.8$ & $0.7 \pm 0.1$ & $1.4 \pm 0.5$ & $4.7 \pm 1.2$ & $76.0 \pm 16.4$ & $39.7 \pm 4.0$ \\
\hline & Merlot* & 8 & 2 & $13.5 \pm 0.5$ & $8.7 \pm 0.6$ & $0.6 \pm 0.1$ & $1.2 \pm 0.1$ & $9.7 \pm 7.8$ & $81.0 \pm 10.2$ & $41.3 \pm 7.6$ \\
\hline & Refosco* & 10 & 0 & $13.9 \pm 0.1$ & $5.4 \pm 4.7$ & $0.4 \pm 0.1$ & $3.4 \pm 0.5$ & $9.3 \pm 1.2$ & $87.0 \pm 7.2$ & $7.0 \pm 6.2$ \\
\hline \multirow{2}{*}{ Posavje } & Kerner* & 8 & 1 & $12.5 \pm 0.4$ & $8.0 \pm 2.3$ & $0.3 \pm 0.0$ & $2.8 \pm 0.0$ & $19.5 \pm 6.4$ & $104.0 \pm 1.4$ & $31.5 \pm 0.7$ \\
\hline & Blaufränkisch*** & 2 & 5 & 11.8 & 7.9 & 0.2 & 2.5 & 13.0 & 102.0 & 29.0 \\
\hline \multirow{3}{*}{ Podravje } & Chardonnay* & 4 & 0 & $13.0 \pm 0.3$ & $8.1 \pm 0.8$ & $0.3 \pm 0.1$ & $3.7 \pm 0.6$ & $12.3 \pm 7.6$ & $73.0 \pm 14.0$ & $32.0 \pm 0.0$ \\
\hline & Zweigelt** & 7 & 0 & $12.0 \pm 0.3$ & $10.0 \pm 2.3$ & $0.2 \pm 0.0$ & $3.0 \pm 0.1$ & $18.0 \pm 2.8$ & $135.5 \pm 6.4$ & $34.0 \pm 4.2$ \\
\hline & Furmint ${ }^{* * *}$ & 0 & 6 & 9.6 & 4.0 & 0.2 & 4.5 & 21.0 & 85.0 & 26.0 \\
\hline
\end{tabular}

*Completion of three spontaneous alcoholic fermentations (average value \pm S.D.)

**Completion of two spontaneous alcoholic fermentations (average value \pm S.D.)

***Completion of one spontaneous alcoholic fermentation (only data for one fermentor are shown)

The variety where all three alcoholic fermentations were stuck is not shown (Blaufränkisch from Podravje, where additional four nonSaccharomyces yeasts were isolated) 


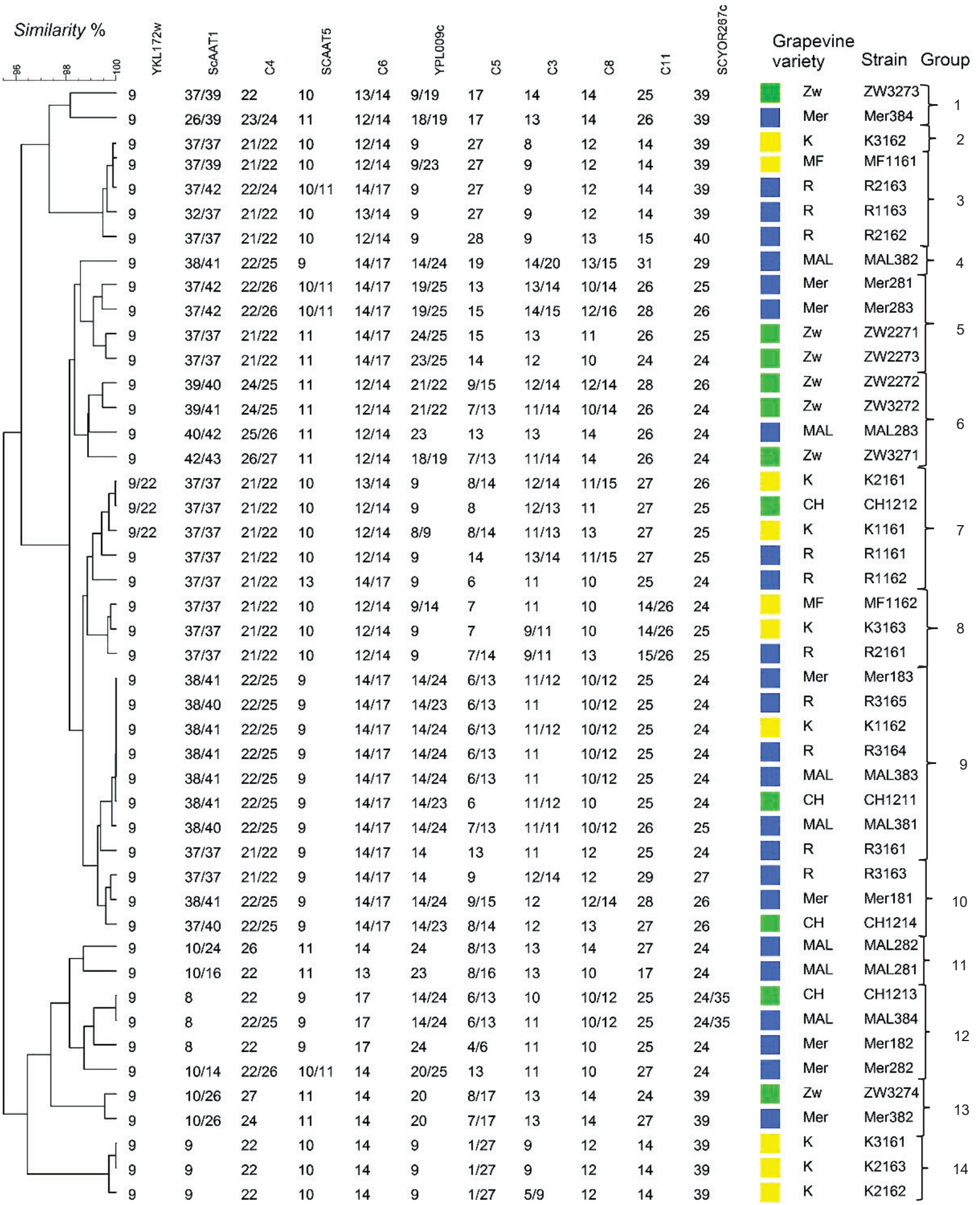

Fig. 2. Dendrogram of the similarity of 46 S.cerevisiae strains isolated from different vine-growing regions: Primorska (blue square), Podravje (green square) and Posavje (yellow square) and varieties (MAL=Malvasia, $\mathrm{MER}=$ Merlot, $\mathrm{R}=$ Refosco, $\mathrm{K}=\mathrm{Kerner}, \mathrm{MF}=\mathrm{Blaufränkisch,} \mathrm{CH}=\mathrm{Chardon}$ nay, ZW=Zweigelt), further analysed with 11 microsatellite loci (YKL172w, ScAAT1, C4, SCAAT5, C6, YPL009c, C5, C3, C8, C11 and SCYOR267c). The numbers below each microsatellite locus represent strain ploidy; homozygous strain has a single allele at a single microsatellite locus, and two different alleles present a heterozygous diploid 


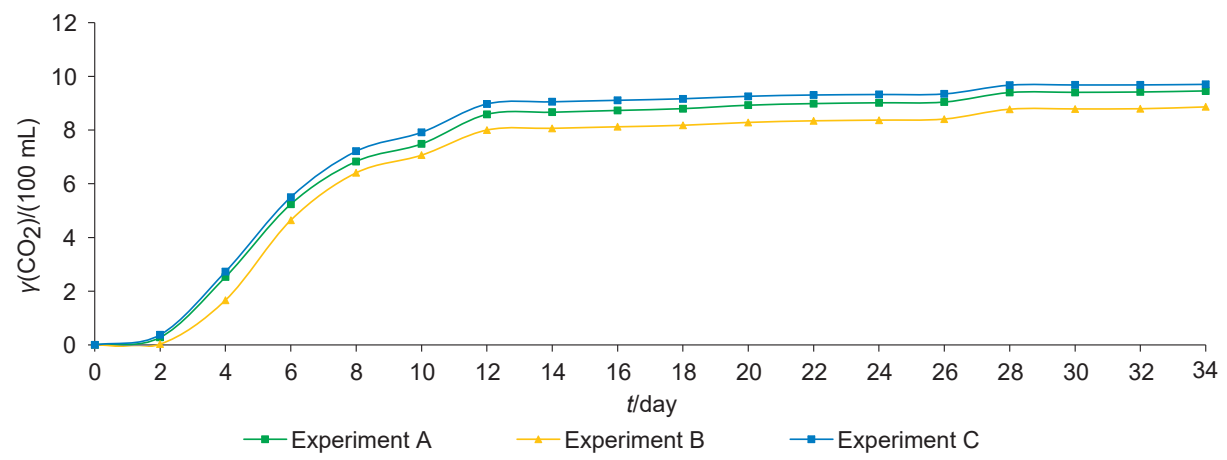

Fig. 3. Mass concentration of exhausted $\mathrm{CO}_{2}$ during alcoholic fermentation with inoculated indigenous Saccharomyces cerevisiae, Hanseniaspora uvarum and Starmerella bacillaris strains at different initial ratios (in experiment A:33:33:33, experiment B: 20:40:40 and experiment C: 80:10:10) in $1000-\mathrm{mL}$ flasks (two replicates; average values \pm S.D. are shown)

the concentration of reducing sugars was $(10.8 \pm 0.0) \mathrm{g} / \mathrm{L}$ in experiments $A$ and $B$, and $(10.7 \pm 0.1) \mathrm{g} / \mathrm{L}$ in experiment $\mathrm{C}(\mathrm{Ta}-$ ble 4). The alcohol volume fraction was significantly lower in the fermentors with the lowest initial ratio of $S$. cerevisiae (experiment B) $((11.4 \pm 0.0) \%)$. The differences in glycerol concentration were not significant, while the volatile acidity was significantly higher in experiment $B((0.86 \pm 0.0) \mathrm{g} / \mathrm{L})$ and significantly lower in experiment $C((0.57 \pm 0.0) \mathrm{g} / \mathrm{L})$ than in experiment $A((0.65 \pm 0.0) \mathrm{g} / \mathrm{L})$. The significantly higher concentrations of free $\mathrm{SO}_{2}$ and total $\mathrm{SO}_{2}$ were in experiment $\mathrm{A}$ $((9.0 \pm 0.4) \mathrm{mg} / \mathrm{mL}$ and $(61.0 \pm 1.2) \mathrm{mg} / \mathrm{mL})$, where the ratio of yeasts was equal.
The concentrations of volatile thiols ( $3 \mathrm{MHA}, 3 \mathrm{MH}$ and $4 \mathrm{MMP}$ ) were determined in the wine samples 14 days after the alcoholic fermentation was completed (Table 4). The concentrations of all three volatile thiols exceeded the limits of sensory perception in wine. The significantly lowest concentration of 3MHA was measured in experiment B (169 ng/L). The combination of yeasts in experiment $B$ released the lowest concentrations of $3 \mathrm{MH}(1344 \mathrm{ng} / \mathrm{L})$, compared to the other two combinations (2005 and $2310 \mathrm{ng} / \mathrm{L}$, respectively). Yeasts in experiment $C$ released significantly higher concentrations of 3MHA (254 ng/L), with S. cerevisiae being predominant; therefore, individual yeast strains have different genetic and

Table 4. Chemical composition of wines obtained in different experiments in 1000-mL fermentors

\begin{tabular}{|c|c|c|c|c|}
\hline Chemical parameter & Experiment $\mathrm{A}$ & Experiment B & Experiment $C$ & $\begin{array}{l}\text { Sensory perception } \\
\text { threshold }\end{array}$ \\
\hline$\varphi($ alcohol $) / \%$ & $(12.1 \pm 0.1)^{b}$ & $(11.4 \pm 0.0)^{\mathrm{a}}$ & $(12.4 \pm 0.1)^{b}$ & / \\
\hline$\gamma($ glycerol $) /(\mathrm{g} / \mathrm{L})$ & $(7.8 \pm 0.2)^{a}$ & $(7.6 \pm 0.1)^{\mathrm{a}}$ & $(7.6 \pm 0.2)^{\mathrm{a}}$ & I \\
\hline$\gamma($ acetic acid $) /(g / L)$ & $(0.65 \pm 0.00)^{b}$ & $(0.86 \pm 0.00)^{c}$ & $(0.57 \pm 0.0)^{\mathrm{a}}$ & / \\
\hline$\gamma\left(\right.$ free $\left.\mathrm{SO}_{2}\right) /(\mathrm{mg} / \mathrm{L})$ & $(9.0 \pm 0.4)^{\mathrm{b}}$ & $(7.0 \pm 0.8)^{\mathrm{a}}$ & $(7.0 \pm 0.4)^{\mathrm{a}}$ & / \\
\hline$\gamma\left(\right.$ total $\left.\mathrm{SO}_{2}\right) /(\mathrm{mg} / \mathrm{L})$ & $(61.0 \pm 1.2)^{\mathrm{a}}$ & $(57.0 \pm 0.8)^{\mathrm{a}}$ & $(60.0 \pm 1.2)^{\mathrm{a}}$ & ( \\
\hline$\gamma$ (reducing sugars)/(g/L) & $(10.8 \pm 0.0)^{a}$ & $(10.8 \pm 0.0)^{\mathrm{a}}$ & $(10.7 \pm 0.0)^{\mathrm{a}}$ & 1 \\
\hline \multicolumn{5}{|l|}{$\gamma($ volatile thiols $) /(\mathrm{ng} / \mathrm{L})$} \\
\hline $3 \mathrm{MHA}$ & $(234.0 \pm 77.8)^{\mathrm{ab}}$ & $(169.0 \pm 35.5)^{\mathrm{a}}$ & $(254.0 \pm 2.3)^{\mathrm{b}}$ & 4 \\
\hline $3 \mathrm{MH}$ & $(2005 \pm 14)^{b}$ & $(1344 \pm 124)^{a}$ & $(2310 \pm 64)^{b}$ & 60 \\
\hline 4MMP & $(11.0 \pm 1.8)^{\mathrm{a}}$ & $(31.0 \pm 19.4)^{\mathrm{a}}$ & $(26.0 \pm 16.1)^{\mathrm{a}}$ & 0.8 \\
\hline \multicolumn{5}{|c|}{$\begin{array}{l}\gamma \text { (acetaldehyde, ethylacetate or } \\
\text { higher alcohols }) /(\mathrm{mg} / \mathrm{L})\end{array}$} \\
\hline Acetaldehyde & $(44.0 \pm 4.5)^{\mathrm{a}}$ & $(40.0 \pm 1.0)^{\mathrm{a}}$ & $(35.0 \pm 1.5)^{\mathrm{a}}$ & $100-125$ \\
\hline Ethylacetate & $(48.0 \pm 2.5)^{\mathrm{a}}$ & $(48.0 \pm 2.0)^{\mathrm{a}}$ & $(48.0 \pm 2.5)^{\mathrm{a}}$ & 15 \\
\hline 1-propanol & $(9.0 \pm 0.0)^{\mathrm{a}}$ & $(9.0 \pm 1.0)^{\mathrm{a}}$ & $\left(10.0 \pm 0.0^{\mathrm{a}}\right.$ & 40 \\
\hline 2-methylpropanol & $(20.0 \pm 0.5)^{\mathrm{b}}$ & $(16.0 \pm 0.0)^{\mathrm{a}}$ & $(21.0 \pm 0.0)^{\mathrm{b}}$ & 40 \\
\hline 1-butanol & $(3.0 \pm 0.0)^{\mathrm{a}}$ & $(3.0 \pm 0.0)^{\mathrm{a}}$ & $(3.0 \pm 0.0)^{\mathrm{a}}$ & 30 \\
\hline 2-methylbutanol & $(27.0 \pm 1.0)^{\mathrm{b}}$ & $(22.0 \pm 0.5)^{\mathrm{a}}$ & $(31.0 \pm 0.0)^{b}$ & 15 \\
\hline 3-methylbutanol & $(94.0 \pm 4.5)^{b}$ & $(79.0 \pm 0.0)^{\mathrm{a}}$ & $(105.0 \pm 0.0)^{b}$ & 30 \\
\hline 2-phenylethanol & $(69.0 \pm 1.0)^{\mathrm{a}}$ & $(69.0 \pm 0.5)^{\mathrm{a}}$ & $(82.0 \pm 3.0)^{\mathrm{b}}$ & 10 \\
\hline
\end{tabular}

Alcoholic fermentations inoculated with different ratios of indigenous Saccharomyces cerevisiae, Hanseniaspora uvarum and Starmerella bacillaris strains: experiment $A=33: 33: 33$, experiment $B=20: 40: 40$ and experiment $C=80: 10: 10$. The letters in superscript in columns indicate statistically significant differences among experiments at a confidence level of $95 \%$. The values in bold indicate the compounds that exceed sensory perception threshold 
psychological abilities to release volatile thiols from their precursors and to convert $3 \mathrm{MH}$ to $3 \mathrm{MHA}$ (34). For the concentration of 4MMP, no significant difference was confirmed. However, in experiment $B$ the highest concentration of $4 M M P$ was measured (31 ng/L), and in experiment $A$ the lowest ( $11 \mathrm{ng} / \mathrm{L}$ ). Numerous studies have shown that the amount of released 4MMP in wine depends on the strain of wine yeasts used for alcoholic fermentation $(37,38)$.

The concentrations of ethyl acetate, acetaldehyde and higher alcohols in wines were measured 45 days after the completion of alcoholic fermentation (Table 4). At concentrations below $300 \mathrm{mg} / \mathrm{L}$ (8), higher alcohols gave the wines the desired complexity and improved their sensory quality, as it was noticed in all three experiments. The concentrations of ethyl acetate, 2-methylbutanol, 3-methylbutanol and 2-phenylethanol exceeded the sensory perception threshold in wine. Compounds 2-butanol and 2-propenyl alcohol in wines were below the limit of detection. Regardless of the composition of the yeast strains, the same amount of ethyl acetate was produced, although many studies have shown that more ethyl acetate is released in mixed alcoholic fermentations in which the ratio of non-Saccharomyces yeasts was higher (39). Various yeast strains affected the profile and concentration of the higher alcohols in the wine. The significantly higher concentrations of 2-methylpropanol, 2-methylbutanol, 3-methylbutanol and 2-phenylethanol were measured in experiment $\mathrm{C}$, with the highest ratio of $\mathrm{S}$. cerevisiae. Moreira et al. (40) reported higher concentrations of 1-propanol, which is known for its harsh heavy odour, in mixed alcoholic fermentations with non-Saccharomyces and Saccharomyces yeasts. However, we measured concentrations of 1-propanol far below the sensory perception threshold.

\section{CONCLUSIONS}

In this study, we observed the fermentative yeast microbiota during the spontaneous alcoholic fermentation of must of different grape varieties from three vine-growing regions in Slovenia. Our main objective was to obtain oenologically interesting strains for further use in inoculated alcoholic fermentations. The spontaneous alcoholic fermentations had different dynamics, and when stopped, different concentrations of unfermented sugars in the must were measured. Some spontaneous fermentations also got stuck. The result of such processes depends on the composition and initial count of the fermentative yeast species and strains and the must composition, especially the sugar content, yeast assimilable nitrogen and vitamin concentrations.

Furthermore, we evaluated eleven microsatellite markers to determine genetic diversity of $46 \mathrm{~S}$. cerevisiae strains. From the obtained results it would be difficult to confirm a link between the location/region and the isolated Saccharomyces cerevisiae strains. Representatives of the same dendrogram groups or their close neighbouring groups occur in almost all vineyard areas. We have checked the databases and these are not known strains from yeast starter cultures.
Different initial ratios of indigenous Saccharomyces and non-Saccharomyces yeasts inoculated in the must influenced the fermentation kinetics and the concentration of volatile and non-volatile compounds in the wine. In our study, we confirmed the best results in a combination dominated by S. cerevisiae $(80$ $\%$ ) and Hanseniaspora uvarum and Stamerella bacillaris with 10 $\%$ each, as this combination led to an appropriate volume fraction of alcohol, a lower concentration of acetic acid and the significantly highest concentrations of volatile thiols and higher alcohols. The combination with only $20 \%$ S. cerevisiae gave the lowest volume fraction of ethanol, which could be interesting for the production of low-alcohol wines. However, this combination produced the highest concentration of acetic acid and significantly lower concentrations of $3 \mathrm{MHA}, 3 \mathrm{MH}, 2$-methylpropanol, 2-methylbutanol, 3-methylbutanol and 2-phenylethanol.

We confirmed the potential use of indigenous $S$. cerevisiae and non-Saccharomyces yeasts in inoculated alcoholic fermentations, which allows the positive properties of the yeast strains to be expressed and good quality wines to be produced. Thus, the results are encouraging for winemakers to create different wine styles associated with a particular terroir using indigenous yeasts.

\section{ACKNOWLEDGEMENTS}

The authors would like to thank the wineries Vinakoper, Klenart, Kartuzija Pleterje, Puklavec Family Wines and Marof for providing the grapes and Dr H. Baša Česnik for the analysis of aromatic compounds.

\section{FUNDING}

This work was funded by the Slovenian Research Agency (ARRS) - young researcher grant number 38190 to Ms Zabukovec.

\section{CONFLICT OF INTEREST}

The authors declare that they have no conflict of interest.

\section{SUPPLEMENTARY MATERIALS}

All supplementary materials are available at: www.ftb. com.hr.

\section{AUTHORS' CONTRIBUTION}

Polona Zabukovec participated in data collection, data analysis and interpretation. She also drafted the manuscript and carried out a partial revision. Neža Čadež supervised the part of the yeast identification and interpretation of the results obtained. She also made a final revision of the manuscript. Franc Čuš contributed with the idea and design of the experiment, participated in the processing of the results and in the drafting and revision of the manuscript, and carried out the final critical revision and approval of the version to be published. 


\section{ORCID ID}

P. Zabukovec (ㅇ https://orcid.org/0000-0002-0824-4910

N. Čadež 우 https://orcid.org/0000-0002-4987-0539

F. Čuš (1) https://orcid.org/0000-0001-8009-8391

\section{REFERENCES}

1. Capozzi V, Garofalo C, Chiriatti MA, Grieco F, Spano G. Microbial terroir and food innovation: The case of yeast biodiversity in wine. Microbiol Res. 2015;181:75-83.

https://doi.org/10.1016/j.micres.2015.10.005

2. Martínez C, Cosgaya P, Vásquez C, Gac S, Ganga A. High degree of correlation between molecular polymorphism and geographic origin of wine yeast strains. J Appl Microbiol. 2007;103(6):2185-95.

https://doi.org/10.1111/j.1365-2672.2007.03493.x

3. Grangeteau C, Gerhards D, von Wallbrunn C, Alexandre H, Rousseaux S, Guilloux-Benatier M. Persistence of two non-Saccharomyces yeasts (Hanseniaspora and Starmerella) in the cellar. Front Microbiol. 2016;7:268.

https://doi.org/10.3389/fmicb.2016.00268

4. Jolly NP, Varela C, Pretorius IS. Not your ordinary yeast: Non-Saccharomyces yeasts in wine production uncovered. FEMS Yeast Res. 2014;14(2):215-37. https://doi.org/10.1111/1567-1364.12111

5. Blateyron L, Sablayrolles JM. Stuck and slow fermentations in enology: Statistical study of causes and effectiveness of combined additions of oxygen and diammonium phosphate. J Biosci Bioeng. 2001;91(2):184-9.

https://doi.org/10.1016/S1389-1723(01)80063-3

6. Csoma H, Zakany N, Capece A, Romano P, Sipiczki. Biological diversity of Saccharomyces yeasts of spontaneously fermenting wines in four wine regions: Comparative genotypic and phenotypic analysis. Int J Food Microbiol. 2010;140(2-3):239-48.

https://doi.org/10.1016/j.ijfoodmicro.2010.03.024

7. Čadež N, Zupan J, Raspor P. The effect of fungicides on yeast communities associated with grape berries. FEMS Yeast Res. 2010;10(5):619-30.

https://doi.org/10.1111/j.1567-1364.2010.00635.x

8. Čuš $F$, Jenko $M$. The influence of yeast strains on the composition and sensory quality of Gewürztraminer wine. Food Technol Biotechnol. 2013;51(4):547-53.

9. Čuš F, Zabukovec $P$, Schroers HJ. Indigenous yeasts perform alcoholic fermentation and produce aroma compounds in wine. Czech J Food Sci. 2017;35(4):329-45. https://doi.org/10.17221/398/2016-CJFS

10. Berthels NJ, Cordero Otero RR, Bauer FF, Thevelein JM, Pretorius IS. Discrepancy in glucose and fructose utilization during fermentation by Saccharomyces cerevisiae wine yeast strains. FEMS Yeast Res. 2004;4(7):683-9.

https://doi.org/10.1016/j.femsyr.2004.02.005
11. Drumonde-Neves J, Franco-Duarte R, Lima T, Schuller D, Pais C. Yeast biodiversity in vineyard environments is increased by human intervention. PLoS ONE. 2016;11(8):e0160579. https://doi.org/10.1371/journal.pone.0160579

12. Schuller D, Cardoso F, Sousa S, Gomes P, Gomes AC, Santos MAS, Casal M. Genetic diversity and population structure of Saccharomyces cerevisiae strains isolated from different grape varieties and winemaking regions. PLoS ONE. 2012;7(2):e32507.

https://doi.org/10.1371/journal.pone.0032507

13. Knight S, Klaere S, Fedrizzi B, Goddard MR. Regional microbial signatures positively correlate with differential wine phenotypes: Evidence for a microbial aspect to terroir. Sci Rep. 2015;5:14233.

https://doi.org/10.1038/srep14233

14. Raspor P, Miklič Milek D, Polanc J, Smole Možina S, Čadež N. Yeasts isolated from three varieties of grapes cultivated in different locations of the Dolenjska vine-growing region, Slovenia. Int J Food Microbiol. 2006;109(1-2):97-102.

https://doi.org/10.1016/j.jjfoodmicro.2006.01.017

15. Swiegers JH, Kievit RL, Siebert T, Lattey KA, Bramley BR, Francis IL, et al. The influence of yeast on the aroma of Sauvignon Blanc wine. Food Microbiol. 2009;26(2):204-11. https://doi.org/10.1016/j.fm.2008.08.004

16. Baffi MA, Santos Bezerra C, Arévalo-Villena M, Isabel Briones-Pérez Al, Gomes E, Silva R. Isolation and molecular identification of wine yeasts from a Brazilian vineyard. Ann Microbiol. 2011;61:75-8.

https://doi.org/10.1007/s13213-010-0099-z

17. Capece A, Granchi L, Guerrini S, Mangani S, Romaniello R, Vincenzini M, Romano P. Diversity of Saccharomyces cerevisiae strains isolated from two Italian wine-producing regions. Front Microbiol. 2016;7:1018.

https://doi.org/10.3389/fmicb.2016.01018

18. Feng L, Jia H, Wang J, Qin Y, Liu Y, Song Y. Selection of indigenous Saccharomyces cerevisiae strains for winemaking in northwest China. Am J Enol Vitic. 2019;70(2):115-26.

https://doi.org/10.5344/ajev.2018.18035

19. Schvarczová E, Štefániková J, Jankura E, Kolek E. Selection of autochtonous Saccharomyces cerevisiae strains for production of typical Pinot Gris wines. J Food Nutr Res. 2017;56(4):389-97.

20. Stefanini I, Albanese D, Sordo M, Legras JL, De Filippo C, Cavalieri D, Donati C. Saccharomyces IDentifier, SID: Strainlevel analysis of Saccharomyces cerevisiae populations by using microsatellite meta-patterns. Sci Rep. 2017;7:15343. https://doi.org/10.1038/s41598-017-15729-3

21. Kemsawasd V, Viana T, Ardö Y, Arneborg N. Influence of nitrogen sources on growth and fermentation performance of different wine yeast species during alcoholic fermentation. Appl Microbiol Biotechnol. 2015;99(23):10191-207. https://doi.org/10.1007/s00253-015-6835-3 
22. Richards KD, Goddard MR, Gardner RC. A database of microsatellite genotypes for Saccharomyces cerevisiae. Antonie van Leeuwenhoek. 2009;96(3):355-9.

https://doi.org/10.1007/s10482-009-9346-3

23. Method OIV-MA-AS313-01:R2015. Total acidity (Oeno 551/2015). Compendium of International Methods of Analysis - OIV. Paris, France: International Organisation of Vine and Wine; 2018:1-3.

24. Method OIV-MA-AS313-15:R2011. pH (A 31, revision by Oeno 438-2011). Compendium of International Methods of Analysis - OIV. Paris, France: International Organisation of Vine and Wine; 2018:1-3.

25. Method OIV-MA-AS4-01. Microbiological analysis of wines and musts. Detection, differentiation and counting of microorganisms (Resolution OIV-Oeno 206/2010).Compendium of International Methods of Analysis - OIV. Paris, France: International Organisation of Vine and Wine; 2016:1-32.

26. White TJ, Bruns T, Lee S, Taylor J. Amplification and direct sequencing of fungal ribosomal RNA genes for phylogenetics. In: Innis MA, Gelfand DH, Sninsky JJ, White TJ, editors. PCR protocols: A guide to methods and applications. New York, NY, USA: Academic Press; 1990. pp. 315-22.

https://doi.org/10.1016/B978-0-12-372180-8.50042-1

27. Kurtzman $C P$, Robnett $C J$. Identification and phylogeny of ascomycetous yeasts from analysis of nuclear large subunit (26S) ribosomal DNA partial sequences. Antonie van Leeuwenhoek.1998;73:331-71.

https://doi.org/10.1023/A:1001761008817

28. BioNumerics v. 7.6, Applied Maths NV, Sint-Martens-Latem, Belgium; 2016. Available from: https://www.appliedmaths.com/download/software.

29. National Center for Biotechnology Information (NCBI). Bethesda, MD, USA: National Library of Medicine, National Center for Biotechnology Information; 1988. Available from: https://www.ncbi.nlm.nih.gov/.

30. Legras JL, Merdinoglu D, Cornuet JM, Karst F. Bread, beer and wine: Saccharomyces cerevisiae diversity reflects human history. Mol Ecol. 2007;16(10):2091-102.

https://doi.org/10.1111/j.1365-294X.2007.03266.x

31. Jenko M, Lisjak K, Košmerl T, Čuš F. The influence of yeast strain combinations on the quality of Sauvignon Blanc wine. Food Sci Technol Res. 2013;19(1):7-15.

https://doi.org/10.3136/fstr.19.7
32. Bavčar D, Baša Česnik H, Čuš F, Košmerl T. The influence of skin contact during alcoholic fermentation on the aroma composition of Ribolla Gialla and Malvasia Istriana Vitis vinifera (L.) grape wines. Int J Food Sci Technol. 2011;46(9):1801-8.

https://doi.org/10.1111/j.1365-2621.2011.02679.x

33. Statgraphics ${ }^{\circledR}$ Centurion XVI, Statpoint Technologies, Inc, Warenton, VA, USA; 2010. Available from: www.statgraphics.com.

34. Yanagida F, Ichinose F, Shinohara T, Goto S. Distribution of wild yeasts in the white grape varieties at Central Japan. J Gen Appl Microbiol. 1992;38(5):501-4.

https://doi.org/10.2323/jgam.38.501

35. Nemcová K, Breierová E, Vadkertiová R, Molnárová J. The diversity of yeasts associated with grapes and musts of the Strekov winegrowing region, Slovakia. Folia Microbiol. 2015;60(2):103-9.

https://doi.org/10.1007/s12223-014-0347-x

36. Jubany S, Tomasco I, Ponce de León I, Medina K, Carrau F, Arrambide N, et al. Toward a global database for the molecular typing of Saccharomyces cerevisiae strains. FEMS Yeast Res. 2008;8(3):472-84.

https://doi.org/10.1111/j.1567-1364.2008.00361.x

37. Swiegers JH, Kievit RL, Siebert T, Lattey KA, Bramley BR, Francis IL, et al. The influence of yeast on the aroma of Sauvignon Blanc wine. Food Microbiol. 2009;26(2):204-11. https://doi.org/10.1016/j.fm.2008.08.004

38. Howell KS, Klein M, Swiegers JH, Hayasaka Y, Elsey GM, Fleet $\mathrm{GH}$, et al. Genetic determinants of volatile-thiol release by Saccharomyces cerevisiae during wine fermentation. Appl Environ Microbiol. 2005;71(9):5420-6. https://doi.org/10.1128/AEM.71.9.5420-5426.2005

39. Rojas V, Gil JV, Piñaga F, Manzanares P. Acetate ester formation in wine by mixed cultures in laboratory fermentations. Int J Food Microbiol. 2003;86(1-2):181-8.

https://doi.org/10.1016/S0168-1605(03)00255-1

40. Moreira N, Pina C, Mendes F, Couto JA, Hogg T, VasconceIos I. Volatile compounds contribution of Hanseniaspora guilliermondii and Hanseniaspora uvarum during red wine vinifications. Food Control. 2011;22(5):662-7. https://doi.org/10.1016/j.foodcont.2010.07.025 